\title{
Students Are Not Highly Familiar with Astronomy Concepts - But What about the Teachers?
}

\author{
Kasım Kıroğlu \\ Correspondence: Kasım Kıroğlu, College of Education Department of Primary Education, Ondokuz Mayıs University, \\ Samsun, Turkey
}

Received: April 7, 2015 Accepted: April 21, $2015 \quad$ Online Published: April 29, 2015

doi:10.11114/jets.v3i4.754

URL: http://dx.doi.org/10.11114/jets.v3i4.754

\begin{abstract}
This study aims to assess primary school teachers' knowledge of basic astronomy concepts, such as the sizes and shapes of, and the distances between, the Sun, the Earth, and the Moon, lunar and solar eclipses, and the motions of the Moon and the Earth. Out of a total of 1,533 teachers, $398(26 \%)$ were reached and asked to take a knowledge test. On the knowledge test, the overall performance of the teachers, whose task it is to teach the astronomy concepts in the fifth grade Science and Technology curriculum, stands at $70 \%$ while the students' success rate is approximately $50 \%$. It is noteworthy that approximately one out of every three teachers answered the questions incorrectly. In this study, the primary school teachers' low performance on the same questions as the students can be observed as an indicator of this. Placing an astronomy course in undergraduate level in the elementary school teacher-training program could be useful. Thus, pre-service teachers have enough knowledge regarding astronomy subjects before starting their careers.
\end{abstract}

Keywords: astronomy concept, primary school teacher, primary school student, misconception, knowledge level

\section{Introduction}

Most people think of astronomy as a set of concepts that are irrelevant to daily life and quite difficult to grasp. In fact, astronomy is at the centre of our daily lives, guiding us in matters ranging from measuring time to forming calendars and from understanding daily meteorological events to long-term climate changes. As an indispensable part of our daily lives, astronomy facilitates rational thinking and allows us to understand the nature of science, which correlates with how accurately and effectively astronomy is taught. When astronomy concepts are properly learned, students' perception, comprehension, and three-dimensional thinking skills improve, which, in turn, facilitates the learning of other abstract concepts that occur in science education. Although astronomy is the oldest branch of science, studies on its teaching do not go back particularly far. With the launch of the Sputnik into space in 1957, studies on the teaching of astronomy began to proliferate, and during this process, developed countries have restructured their educational curricula both to maintain their pace in the space race and to familiarise their citizens with scientific concepts. This restructuring brought the teaching of astronomy to the foreground and, to this end, gave rise to a large body of recent research on how-and how much-people understand the basic concepts of astronomy (Lelliott \& Rollnick, 2010). These studies mostly focus on primary school, secondary school, and university students' as well as student-teachers' knowledge of basic astronomy (Kalkan \& Kiroglu, 2007; Trumper, 2001a; Zeilik, Schau, \& Mattern, 1998), and the studies reveal major difficulties regarding the understanding of such concepts as the sizes and shapes of, and the distances between, the Sun, the Earth, and the Moon, lunar and solar eclipses, and the motions of the Moon and the Earth. In their study with first-, third-, and fifth-year primary school pupils on the day and night cycle, Vosniadou and Brewer (1994) concluded that the students were not fully able to pinpoint the positions of the Earth, the Sun, and the Moon. According to Dunlop (2000), many children have difficulty understanding some concepts in astronomy, such as the size and shape of the Earth; the cause of day and night; the cause of seasons; and the movements of the Earth, the Sun, and the Moon. In a similar vein, Klein (1982) and Jones et al. (1987) have found that few primary school pupils are actually able to model the relationships between the Sun, the Earth, and the Moon. Valanides et al. (2000) and Sharp (1995), revealed the confusion among students about the Earth's rotation about its axis and its orbit around the Sun.

In fact, students' apparent confusion about such concepts should not come as much of a surprise. Studies show that this confusion is shared by pre-service teachers and full teachers. Zeilik et al. (1998) reported that university students have misconceptions about the lunar eclipse, the Moon's motion, the solar eclipse, and the solar angle. Trundle, Atwood, and Christopher (2002) revealed student-teachers' misconceptions of such basic astronomy concepts as the phases of the 
Moon and the orbit of the Earth. According to Brunsell and Marcks (2005), a teacher's scientific understanding has a dramatic impact on the students' ability to learn science. The results show that these teachers are lacking a deep, coherent understanding of astronomy concepts. Another study points to a strong correlation between the teachers' test scores and the students' test scores (Ballou \& Podgursky, 1997). Underlying these misconceptions are the teachers' and students' traditionally acquired unscientific knowledge and experiences, the inadequacy of many teachers in astronomy and astronomy education, and a lack of resources available in astronomy (Pasachoff \& Percy, 2005). It has also been found that some teachers deliberately avoid astronomy subjects for lack of confidence and quality resources (Slater, Safko, \& Carpenter, 1999). Additionally, superficial content understanding leads teachers to emphasise memorisation of isolated facts and limits their ability to teach in a creative and innovative manner, making them afraid to introduce lessons that may encourage students to move beyond the teacher's knowledge (Gess-Newsome, 2001). Lower-level questioning and cookbook activities dominate the instructional practices of teachers with limited content knowledge. These teachers also limit the use of student questions in classroom discourse and the development of conceptual connections, and they often misrepresent the nature of the discipline (Brunsell \& Marcks, 2005).

As a review of the literature also suggests, at the root of students' and student-teachers' misconceptions about astronomy is the way in which they were actually taught these concepts by their teachers. Burdened with the greatest responsibility, primary school teachers need to be adequately equipped in the basics of astronomy. In addition to the teachers' knowledge of astronomy, the methods and models that are used to teach these concepts are of paramount importance. Prior to the methods employed or the use of existing models, the teacher's grasp of the subject is crucial. A good way to ascertain teachers' level of knowledge would be to evaluate their performance on an astronomy test that their own students took. In the particular context of Turkey, this testing would entail evaluating the teachers' performance on the astronomy questions in the nationwide examinations that are administered to primary school pupils. The Free Admission and Scholarship Tests for Boarding Schools (FASTBS) is one of the most important of these examinations in Turkey. The FASTBS, which is a large-scale test similar to the GRE, the GMAT, and the SAT, is administered to socio-economically underprivileged students in accordance with Article 42 of the Turkish Constitution and the principle of 'equal opportunities' of the National Education Act. Composed of a total of 100 items in Mathematics, Turkish, Science and Technology, and Social Studies, the test has 25 Science and Technology questions. Attended by fifth-year primary school students, the FASTBS was last administered in 2011 to approximately 400,000 students. A total of 13 astronomy questions were asked (see the Appendix), including 1 in 2009; 2 in 2007, 2008, and 2010; and 3 in 2006 and 2011.

\subsection{The Purpose of Study}

Based on FASTBS questions, this study aims to assess primary school teachers' knowledge of basic astronomy concepts, such as the sizes and shapes of, and the distances between, the Sun, the Earth, and the Moon, lunar and solar eclipses, and the motions of the Moon and the Earth. This study further aims to compare the students' answers to the astronomy questions in the Science and Technology sections of the FASTBS given between 2006 and 2011 with those given by teachers.

\section{Method}

This study is a survey model aiming to evaluate primary school teachers' knowledge of basic astronomy concepts, such as the sizes and shapes of, and the distances between, the Sun, the Earth, and the Moon, lunar and solar eclipses, and the motions of the Moon and the Earth. Survey research designs are a type of quantitative research in which investigators administer a survey to a sample or to an entire population of people to describe the attitudes, opinions, behaviors, or characteristics of the population (Creswell, 2012).

\subsection{Population and Sample}

The population included in this study is composed of primary school teachers working in schools in the city of Samsun, Turkey. In the selection of the sample, the primary school and teacher numbers were taken into account, and the 'layered sampling' technique was used. The districts within the Metropolitan Municipality of Samsun were taken as layers, and care was taken to select teachers from all of these districts. Out of a total of 1,533 teachers, 398 (26\%) were reached and asked to take a knowledge test. The total numbers of teachers working in these districts and those selected in the sample are shown in Table 1.

Table 1. Research population and sample

\begin{tabular}{lll}
\hline District & Population & Sample \\
\hline İlkadım & 780 & 204 \\
Canik & 300 & 78 \\
Atakum & 280 & 72 \\
Tekkeköy & 173 & 44 \\
Total & 1533 & 398 \\
\hline
\end{tabular}




\subsection{Data Collection Instrument}

The astronomy questions in the Science and Technology sections of the FASTBS(s) administered between 2006 and 2011 to fifth-year primary school pupils were used as the data collection instrument in this study. Permission to use these questions in this study was requested from the Ministry of National Education (MNE). Statistical data showing the year-by-year percentages of the students' right and wrong answers to these questions were also requested from the Ministry such that they could be compared with the answers given by the teachers in this study. In this context, all of the 13 questions on the sizes and shapes of, and the distances between, the Sun, the Earth, and the Moon, lunar and solar eclipses, and the motions of the Moon and the Earth were included in the test, which was administered by the researcher to the primary school teachers. The process of administering knowledge tests is more difficult than other quantitative data collection tools, as it is not easy to eliminate the participants' feeling of 'being tested', or to have them answer the questions without being influenced by one another. For this reason, the researcher asked the principals for help with making the necessary arrangements for the administration of the test, during which time the principals were personally available in the testing rooms.

\subsection{Data Analysis}

The SPSS 16.0 statistical package programme was used for the analysis of the data on primary school teachers' knowledge of astronomy subjects. The answers to the questions were coded as incorrect (0) and correct (1), and the frequencies and percentages of correct and incorrect responses were also evaluated to compare them to the data on the students' answers provided by the MNE.

\section{Results}

In this section, we shall examine the answers given by primary school teachers to the 13 questions from the FASTBS(s) administered between 2006 and 2011 on the size, shape, and movements of the Earth and the Moon, as well as lunar eclipses. The presentation of the findings is centred around the questions on a year-by-year basis and a comparison of the answers given by the students who took the test in that particular year with those given by the teachers who took part in this study. The frequencies and percentages of the answers from both groups are presented in tables.

Three astronomy questions were asked in the FASTBS in 2006. The frequencies and distributions of the answers given by the students who took the test and by the teachers who took part in this study are given in Table 2 .

Table 2. Frequencies and percentage distribution of student and teacher answers

\begin{tabular}{|c|c|c|c|c|c|c|}
\hline \multirow{2}{*}{ Question no } & \multirow{2}{*}{ Group } & \multirow{2}{*}{$\mathrm{N}$} & \multicolumn{2}{|l|}{ Incorrect } & \multicolumn{2}{|l|}{ Correct } \\
\hline & & & $\mathrm{f}$ & $\%$ & $\mathrm{f}$ & $\%$ \\
\hline \multirow{2}{*}{2} & Teachers & 398 & 119 & 29,9 & 279 & 70,1 \\
\hline & Students & 204.535 & 95.506 & 47,0 & 109.029 & 53,0 \\
\hline \multirow{2}{*}{6} & Teachers & 398 & 159 & 39,9 & 239 & 60,1 \\
\hline & Students & 204.535 & 122.042 & 60,0 & 82.493 & 40,0 \\
\hline \multirow{2}{*}{13} & Teachers & 398 & 137 & 34,4 & 261 & 65,6 \\
\hline & Students & 204.535 & 112.293 & 55,0 & 92.242 & 45,0 \\
\hline
\end{tabular}

From Table 2, we can see that question 2 on the time of day modelled on the Earth's rotation was correctly answered by $53 \%$ of the students and $70.1 \%$ of the teachers. Question 6 on the Moon's orbit was correctly answered by $40 \%$ of the students and $60.1 \%$ of the teachers. Question 13 on the motions of the Earth and the Moon was correctly answered by $45 \%$ of the students and $65.6 \%$ of the teachers. It is interesting to note that these three questions on the motions of the Earth and the Moon were answered incorrectly by more than half of the students and by approximately one third of the teachers.

Two astronomy questions were asked in the FASTBS in 2007. The frequencies and distribution of the answers given by the students who took the test and by the teachers who took part in this study are given in Table 3.

Table 3. Frequencies and percentage distribution of student and teacher answers

\begin{tabular}{lllllll}
\hline \multirow{2}{*}{ Question no } & \multirow{2}{*}{ Group } & \multirow{2}{*}{$\mathrm{N}$} & \multicolumn{2}{l}{ Incorrect } & \multicolumn{3}{c}{ Correct } \\
\cline { 4 - 6 } & & & $\mathrm{f}$ & $\%$ & $\mathrm{f}$ & $\%$ \\
\hline \multirow{2}{*}{9} & Teachers & 398 & 237 & 59,5 & 161 & 40,5 \\
& Students & 207.726 & 151.747 & 73,0 & 55.979 & 27,0 \\
\multirow{2}{*}{10} & Teachers & 398 & 150 & 37,7 & 248 & 62,3 \\
& Students & 207.726 & 141.191 & 68,0 & 66.535 & 32,0 \\
\hline
\end{tabular}

From Table 3, we can see that question 9 on the motion of the Earth was correctly answered by $27 \%$ of the students and $40.5 \%$ of the teachers. Question 10 on the Moon's movements was correctly answered by $32 \%$ of the students and $62.3 \%$ 
of the teachers. It is interesting to note that both the students and the teachers did poorly on these two questions from the 2007 test on the motions of the Earth and the Moon.

Two astronomy questions were asked in the FASTBS in 2008. The frequencies and distribution of the answers given by the students who took the test and by the teachers who took part in this study are given in Table 4.

Table 4. Frequencies and percentage distribution of student and teacher answers

\begin{tabular}{lllllll}
\hline \multirow{2}{*}{ Question no } & \multirow{2}{*}{ Group } & \multirow{2}{*}{$\mathrm{N}$} & Incorrect & \multicolumn{2}{c}{ Correct } & \multirow{2}{*}{$\%$} \\
\cline { 4 - 6 } & & & $\mathrm{f}$ & $\%$ & $\mathrm{f}$ & $\%$ \\
\hline \multirow{2}{*}{5} & Teachers & 398 & 62 & 15,6 & 336 & 84,4 \\
& Students & 227.485 & 61.212 & 27,0 & 166.273 & 73,0 \\
\multirow{2}{*}{11} & Teachers & 398 & 121 & 30,4 & 277 & 69,6 \\
& Students & 227.485 & 138.927 & 61,0 & 88.558 & 39,0 \\
\hline
\end{tabular}

From Table 4, we can see that question 5 on the motions of the Earth and the Moon was correctly answered by $73 \%$ of the students and $84.4 \%$ of the teachers. Question 11 on the size and distance of the Sun, the Earth, and the Moon was correctly answered by $39 \%$ of the students and $69.6 \%$ of the teachers. It is interesting to note that both the students and the teachers did well on the question on the motions of the Earth and the Moon, but they did rather poorly on the question on the size and distance of the Sun, the Earth, and the Moon.

Only one astronomy question was asked in the FASTBS in 2009. The frequencies and distribution of the answers given by the students who took the test and by the teachers who took part in this study are given in Table 5 .

Table 5. Frequencies and percentage distribution of student and teacher answers

\begin{tabular}{lllllll}
\hline \multirow{2}{*}{ Question no } & \multirow{2}{*}{ Group } & \multirow{2}{*}{} & \multicolumn{2}{l}{ Incorrect } & \multicolumn{2}{l}{ Correct } \\
\cline { 4 - 7 } & & & $\mathrm{f}$ & $\%$ & $\mathrm{f}$ & $\%$ \\
\hline \multirow{2}{*}{4} & Teachers & 398 & 49 & 12,3 & 349 & 87,7 \\
& Students & 327.721 & 91.519 & 28,0 & 236.202 & 72,0 \\
\hline
\end{tabular}

From Table 5, we can see that question 4 on the motion of the Earth and its distance from the Sun was correctly answered by $72 \%$ of the students and $87.7 \%$ of the teachers. We can conclude that both groups did well on this question.

Two astronomy questions were asked in the FASTBS in 2010. The frequencies and distribution of the answers given by the students who took the test and by the teachers who took part in this study are given in Table 6 .

Table 6. Frequencies and percentage distribution of student and teacher answers

\begin{tabular}{lllllll}
\hline \multirow{2}{*}{ Question no } & \multirow{2}{*}{ Group } & \multirow{2}{*}{$\mathrm{N}$} & \multicolumn{2}{c}{ Incorrect } & \multicolumn{2}{c}{ Correct } \\
\cline { 5 - 7 } & & & $\mathrm{f}$ & $\%$ & $\mathrm{f}$ & $\%$ \\
\hline \multirow{2}{*}{3} & Teachers & 398 & 120 & 30,2 & 278 & 69,8 \\
& Students & 373.317 & 237.855 & 64,0 & 135.462 & 36,0 \\
\multirow{2}{*}{12} & Teachers & 398 & 62 & 15,6 & 336 & 84,4 \\
& Students & 373.317 & 114.520 & 31,0 & 258.797 & 69,0 \\
\hline
\end{tabular}

From Table 6, we can see that question 3 on modelling a lunar eclipse was correctly answered by $36 \%$ of the students and $69.8 \%$ of the teachers. Question 12 on the motions of the Earth and the Moon was correctly answered by $69 \%$ of the students and $84.4 \%$ of the teachers. It is significant that about two thirds of the students and one third of the teachers gave the wrong answer to the question on modelling a lunar eclipse. The teachers did better on the question on the movements of the Earth and the Moon, but approximately one third of the students had difficulty with it.

Three astronomy questions were asked in the FASTBS in 2011. The frequencies and distribution of the answers given by the students who took the test and by the teachers who took part in this study are given in Table 7.

Table 7. Frequencies and percentage distribution of student and teacher answers

\begin{tabular}{|c|c|c|c|c|c|c|}
\hline \multirow{2}{*}{ Question no } & \multirow{2}{*}{ Group } & \multirow{2}{*}{$\mathrm{N}$} & \multicolumn{2}{|l|}{ Incorrect } & Correct & \multirow[b]{2}{*}{$\%$} \\
\hline & & & $\mathrm{f}$ & $\%$ & $f$ & \\
\hline \multirow{2}{*}{1} & Teachers & 398 & 61 & 15,3 & 337 & 84,7 \\
\hline & Students & 399.102 & 195.035 & 49,0 & 204.067 & 51,0 \\
\hline \multirow{2}{*}{7} & Teachers & 398 & 143 & 35,9 & 255 & 64,1 \\
\hline & Students & 399.102 & 243.373 & 61,0 & 155.729 & 39,0 \\
\hline \multirow{2}{*}{8} & Teachers & 398 & 49 & 12,3 & 349 & 87,7 \\
\hline & Students & 399.102 & 200.584 & 51,0 & 198.518 & 49,0 \\
\hline
\end{tabular}

From Table 7, we can see that question 1 on the sizes of the Sun, the Earth, and the Moon was correctly answered by $51 \%$ of the students and $84.7 \%$ of the teachers. Question 7 on the motions of the Earth and the Moon was correctly answered by $39 \%$ of the students and $64.1 \%$ of the teachers. Question 8 on modelling the orbits of the Earth and the Moon in relation to the Sun was correctly answered by $49 \%$ of the students and $87.7 \%$ of the teachers. We can conclude that in 2011, the students did poorly on the three questions on the sizes and motions of the Sun, the Earth, and the Moon, with 
about half the students giving the wrong answer. Apart from question 7 on the movements of the Earth and the Moon, the teachers did well on the test.

\section{Discussion}

This study looks at the 13 astronomy questions asked between 2006 and 2011 in the FASTBS, which were administered nationwide by the Ministry of National Education, the last of which was taken by approximately 400,000 fifth-year primary school pupils. The data from these tests, which were taken by nearly half of the fifth-year primary school pupils throughout Turkey, is quite impressive in that it comes from a sample far larger than any sample used to date in any other study worldwide. All of the astronomy questions asked in these examinations (2006-2011) were compiled to form a 13-item knowledge test to assess the primary school teachers' level of knowledge in this subject. Of these questions, designed by the Ministry of National Education, 10 were related to the motions of the Earth and the Moon, two were related to the sizes of the Sun, the Earth, and the Moon, and one was related to lunar eclipses. The questions were taken from the last six FASTBS, as those up to 2006 contained no astronomy questions.

The teachers' performance on the knowledge test was considered item by item. Taking all of the answers into account, the teachers were found to have an overall success rate of approximately $70 \%$. We can see that question 1 on the sizes of the Sun, the Earth, and the Moon was correctly answered by $51 \%$ of the students and $84.7 \%$ of the teachers. Although this question is similar to question 11, a larger number of the teachers and students answered it correctly because the way it is asked is different. In question 11, answers I, II, and III need to be read and interpreted all at the same time while searching for the correct answer, whereas in question 1, selecting a single answer impacts the performance. In fact, the question is again about the size of objects changing depending on their distance. This difference points to the importance of the way questions about basic concepts are asked.

Question 2 on the time of day modelled on the Earth's rotation was correctly answered by $53 \%$ of the students and $70.1 \%$ of the teachers. The fact that $29.9 \%$ of the teachers gave the wrong answer to this question shows that nearly one third of them have no grasp on the basic relations between the Sun and the planet that we live on. By the very nature of their profession, the teachers should have learned about the day and night cycles, the seasons, and other natural phenomena that arise due to both the Earth's rotation about its axis and its orbit around the Sun. In fact, one would expect them to have experienced and internalised these natural processes throughout their lives. The teachers' performance of $70.1 \%$ and the students' $53 \%$ on this question demonstrate that they have difficulty modelling the interaction between the Sun and the Earth and concretising mostly abstract concepts.

Question 3 on modelling a lunar eclipse was correctly answered by $36 \%$ of the students and $69.8 \%$ of the teachers. This question requires the concretisation of abstract concepts for full comprehension. Although the eclipse could be modelled on objects from daily life, $30.2 \%$ of the teachers could not reach the correct answer, which suggests that they do not use modelling for teaching a difficult-to-grasp subjects in the fifth grade.

Question 4 on the motions of the Earth and its distance from the Sun was correctly answered by $72 \%$ of the students and $87.7 \%$ of the teachers. This question asks about the root cause of the day and night cycles. The teachers' and the students' relatively high scores on this item were anticipated, as the day and the night are natural phenomena encountered and observed by teachers and students alike on a daily basis. Still, it is important to note that $12.3 \%$ of the teachers gave the wrong answer to this question.

Question 5 on the motions of the Earth and the Moon was correctly answered by $73 \%$ of the students and $84.4 \%$ of the teachers. This question relates to how much is known and understood about the interactions between the Sun, the Earth, and the Moon. The movements of the Sun, the Earth, and the Moon are usually taught using models. When the modelling is appropriate, the acquisition can be expected to increase to the level of knowledge and comprehension. Although most teachers answered this question correctly, $15.6 \%$ of them gave the wrong answer to a notably simple and illustrated question.

Question 6 on the Moon's motions was correctly answered by $40 \%$ of the students and $60.1 \%$ of the teachers. The phases of the Moon, the relationships between the Moon, the Sun, and the Earth, and the interactions resulting from these relationships are notoriously difficult to comprehend for both students and teachers (Trumper, 2001b). The basic concept that this question aims to test was illustrated in two dimensions and thus transformed from an abstract into a concrete concept. Nonetheless, $39.9 \%$ of the teachers gave the wrong answer, which indicates a lack of understanding of how the Sun rays illuminate the Moon's surface in a given phase. It seems difficult for teachers and students alike to experience lunar movements in their daily lives. Teachers can only help their students grasp this by question why the Moon changes during a one-month period and by setting up the necessary models.

Question 7 on the motions of the Earth and the Moon was correctly answered by $39 \%$ of the students and $64.1 \%$ of the teachers. This is a variation of question 10. Poor performance on both questions suggests the lack of a full 
understanding by students and teachers alike of the Moon's interactions with the Earth. The interactions between the Sun, the Earth, and the Moon are such that we cannot observe them from our daily experiences. While an observer outside the solar system would be fully able to witness the movements, one on the Earth is unable to do so, which makes the concepts abstract. Teachers therefore need to learn and internalise basic knowledge of the Sun, the Earth, and the Moon scientifically and set up the necessary models while teaching them to their students. Otherwise, misconceptions are inevitable regarding phenomena that are difficult to observe in daily life.

Question 8 on modelling the orbits of the Earth and the Moon in relation to the Sun was correctly answered by $49 \%$ of the students and $87.7 \%$ of the teachers. It is of particular interest that $51 \%$ of the students answered this question incorrectly whereas $27 \%$ of them gave the wrong answer to question 5 , which tested the same acquisition, revealing the significance of modelling in understanding and answering any given question. While the modelling in question 8 is common in textbooks and represents a small part of the system, the one in question 5 is based on the students' own daily experiences. It is therefore understandable that the students scored high on a question using a model that was relevant to themselves and their daily lives.

Question 9 on the motions of the Earth was correctly answered by $27 \%$ of the students and $40.5 \%$ of the teachers. This question aimed to assess whether natural processes that are caused by the Earth's motions have been comprehended. Most teachers and students who gave the wrong answer to this question marked answer (a), probably misled by their knowledge that daylight times vary from zone to zone on Earth.

Question 10 on the Moon's motions was correctly answered by $32 \%$ of the students and $62.3 \%$ of the teachers. All three statements in this question are true. The trick statement is 'When we look at the Moon from the Earth, we always see the same side of it'. The teachers and students who know that the Moon, too, rotates just like the Earth may have figured that not just one but both sides of the Moon can be seen according to its orbit. To interpret the statement 'If the Moon had its own light, it could be observed as a whole', the students would need to have followed the phases of the Moon in their daily lives, know that the Moon is not a source of light, and figure that if it was, there would be no phases of the Moon. 'The Moon completes its rotation and orbit around the Earth within the same period of time' is a statement that a fifth-year pupil can only know through rote learning and cannot grasp as a concept. The student would need to observe that after a month of changes, the Moon goes back to its first phase and also to prove based upon modelling that it takes one month to complete its rotation. The students' poor performance on this question may indicate that they have difficulty concretising the abstractions involved, and this result is understandable for the age group concerned. However, that $37.7 \%$ of the teachers gave the wrong answer to this question means that about two fifths of them do not have an understanding of this subject, even on a knowledge level, which is part of the curriculum.

Question 11 on the size and distance of the Sun, the Earth, and the Moon was correctly answered by $39 \%$ of the students and $69.6 \%$ of the teachers. This question that requires the mundane knowledge that distant objects appear smaller than they actually are. Any student or teacher who can ask themselves why a house on a hill or things from an aircraft window seem small can answer this question. That $30.4 \%$ of the teachers gave the incorrect answer demonstrates that they cannot model in the classroom what they actually observe every single day.

Question 12 on the Earth's and Moon's motions was correctly answered by $69 \%$ of the students and $84.4 \%$ of the teachers. This question requires the use of background knowledge about the given model. It is therefore interesting to note that $15.6 \%$ of the teachers incorrectly answered such an easy question asked about a model.

Question 13 on the motions of the Earth and Moon was correctly answered by $45 \%$ of the students and $65.6 \%$ of the teachers. In the illustration accompanying the question, the observer's location is the Earth, the torch represents the Sun, and the tennis ball represents the Moon. The teachers should have known from daily experience that the Sun is a source of heat and energy, and easily matched it with the torch. Likewise, the teachers should have identified the observer's location as the Earth and matched that accordingly, and finally, they should have matched the tennis ball with the Moon and its four distinct shapes during the month. The students' performance of $45 \%$ on such a complex question may be judged normal. However, the teachers would have been expected to correctly match the objects using their knowledge background, the advanced level of abstractions and concretisations one would expect of them and, of course, their daily experiences.

On the knowledge test, the overall performance of the teachers, whose task it is to teach the astronomy concepts in the fifth grade Science and Technology curriculum, stands at 70\% while the students' success rate is approximately $50 \%$. It is noteworthy that approximately one out of every three teachers answered the questions incorrectly. The teachers' misconceptions about the movements of the Earth and Moon, the consequences of these movements, and the phases of the Moon are apparently passed on to the students. In this study, the primary school teachers' low performance on the same questions as the students can be observed as an indicator of this. In the literature, there are studies demonstrating teachers' misconceptions regarding astronomy topics, similar to the findings of this paper. In their study with British 
primary school teachers, Summer and Mant (1995) concluded that few of the teachers had adequate knowledge of the Earth and the solar system. In a study with primary, secondary, and high school teachers by Brunsell and Marcks (2005), $18 \%$ of the primary school teachers, $33 \%$ of the secondary school teachers, and $32 \%$ of the high school teachers correctly answered a question on the size of the Earth and Moon, and the rates of correct responses on a question on the phases of the Moon were 25\%,53\%, and 63\%, respectively. Brunsell and Marcks further suggest that, if the study were to be repeated with students, the findings would probably overlap. Trundle, Atwood, and Christopher (2002) studied the phases of the Moon with primary school teachers and found an abundance of misconceptions. One of the main reasons for the teachers' inadequacy in astronomy subjects is the inadequate education that they themselves received as university students. Therefore, the findings of the study concerning student-teachers are quite significant in revealing the current situation. Atwood and Atwood (1996) found that only one of the 49 student-teachers had the correct knowledge regarding the occurrence of the seasons, with the rest of them mostly trying to explain the seasons using distance theory. Trundle, Atwood, and Christopher (2002) found that a great majority of student-teachers had misconceptions about the phases of the Moon. In their comparative study with participants from China and New Zealand, Bryce and Blown (2012) found that primary school student-teachers and primary school teachers in both countries lacked the academic jargon to explain - and the skills to model - astronomy subjects, and they had inadequate training in astronomy in general.

\section{Conclusions}

Compared to other concepts in science, astronomy concepts are notably difficult to understand and explain, and they require an upper-level 'cognitive skill' for their comprehension (Rommel, 2010). However, this study, as well as others in the literature, shows that neither teachers nor students have the desired level of knowledge in astronomy subjects, let alone the cognitive level. As noted by Pasachoff and Percy (2005), astronomy subjects are included in the educational curricula in many countries, but the teachers have either insufficient knowledge about these topics, or they have great difficulty transferring what they know to their students. How can we break this vicious circle in which student-teachers with inadequate training have difficulty teaching astronomy when they become teachers? Especially in the country where this study was carried out, where these subjects are usually taught through plain lecturing or two-dimensional drawings on the board, it seems unlikely that this pattern will be broken in the short term. Another question is, if a change is to occur, should the starting point be the student, the student-teacher, or the teacher? Considering these two questions together, it does not seem easy to reach a solution in a setting where teachers are not quite sure how to go about teaching astronomy subjects. As noted by Greenwald, Hedges, and Laine (1996), student progress in astronomy subjects correlates to the quality of the teachers. In-service training for existing teachers in the short term and improving the quality of college education in the long run could be thought of as two solutions to overcome this problem. There are no astronomy courses offered in the curricula of primary education departments, nor are there any other courses in which astronomy subjects are touched upon. The student-teachers learn about them in primary school, and they may study them further in an elective course in secondary school. Having had no astronomy training at a tertiary level, teachers practically teach their students what they learned in primary school. This tendency is quite worth noting. As a useful solution, an astronomy course could be added to the curricula of primary education departments. Considering that astronomy subjects are quite abstract, 3D modelling and materials should be used in student-teacher training, and student-teachers should also be taught how to use these resources in the classroom. Without modelling facilities, such as 3D modelling, it is virtually impossible to teach astronomy subjects to a primary school student, who has a concrete-thinking level of learning, through plain lecturing.

\section{Research Limitations and Future Directions}

Quantitative research methodology was used in this study. In order to explore teachers' and students' mental models, designing a qualitative research could be helpful. Also, some mixed design studies may be conducted in the future.

In this study, the questions were received from FASTBS exams, applied by Turkish National Ministry of Education, between 2006 and 2011. Each question was evaluated separately by comparing teachers and students' answers.

While investigating teachers' astronomy knowledge, some of their demographic information like their genders, ages, work experiences or education levels was ignored. More studies may be conducted to understand these variables' effect on teachers' and students' success in astronomy subjects.

\section{References}

Atwood, R. K., \& Atwood, V. A. (1996). Preservice elementary teachers' conceptions of the causes of seasons. Journal of Research in Science Teaching, 33, 553-563.

http://dx.doi.org/10.1002/(SICI)1098-2736(199605)33:5<553::AID-TEA6>3.0.CO;2-Q

Ballou, D., \& Podgursky, M. J. (1997). Teacher pay and teacher quality, Kalamazoo, Michigan: Upjohn Institute. 
Brunsell, E., \& Marcks, J. (2005). Identify a baseline for teachers' astronomy content knowledge, Astronomy Education Review, 3(2), 38-46. http://dx.doi.org/10.1080/0950069890110503

Bryce, T. G. K., \& Blown, E. J. (2012). The novice-expert continuum in astronomy knowledge. International Journal of Science Education, 34(4), 545-587. http://dx.doi.org/10.1080/09500693.2011.642325

Creswell, J. W. (2012). Educational research: Planning, conducting, and evaluating quantitative and qualitative research (4th ed.). Boston, MA: Pearson

Dunlop, J. (2000). How children observe the universe. Publications of the Astronomical Society of Australia, 17(2), 194-206. http://dx.doi.org/10.1071/AS00194

Gess-Newsome, J. (2001). The professional development of science teachers for science education reform: A review of research, J. Rhoton \& P. Bowers (Eds.) Professional Development Planning and Design, Arlington, VA: NSTA Press.

Greenwald, R., Hedges, L. V., \& Laine, R. D. (1996). The effect of school resources on student achievement. Review of Educational Research, 66(3), 361-396. http://dx.doi.org/10.3102/00346543066003361

Jones, B., Lynch, P., \& Reesink, C. (1987). Children's conceptions of the Earth, Sun and Moon. International Journal of Science Education, 9(1), 43-53. http://dx.doi.org/10.1080/0950069870090106

Kalkan, H., \& Kiroglu, K. (2007). Science and nonscience students' ideas about basic astronomy concepts in preservice training for elemantary school teachers. The Astronomy Education Review, 6 (1), http://dx.doi.org/10.3847/AER2007002

Klein, C. A. (1982). Children's concepts of the Earth and the Sun. Science Education, 65(1), 95-107. http://dx.doi.org/10.1002/sce.3730660112

Lelliott, A., \& Rollnick, M. (2010). Big ideas: A review of astronomy education research 1974-2008. International Journal of Science Education, 32(13), 1771-1799. http://dx.doi.org/10.1080/09500690903214546

Pasachoff, J. M., \& Percy, J. R. (2005). Teaching and learning astronomy: Effective strategies for educators worldwide. New York: Cambridge University Press. http://dx.doi.org/10.1017/CBO9780511614880

Rommel, M. (2010). Urban middle-school teachers' beliefs about astronomy learner characteristics: Implications for curriculum. Astronomy Education Review, 9(1). http://dx.doi.org/10.3847/AER2010030

Sharp, J. (1996). Children's astronomical beliefs: A preliminary study of year 6 children in south-west England. International Journal of Science Education, 18(6), 685-712. http://dx.doi.org/10.1080/0950069960180604

Slater, T. F., Safko, J. L., \& Carpenter, J. R. (1999). Long-term attitude sustainability from a constructivist-based astronomy-for-teachers course, Journal of Geoscience Education, 47, 366-368.

Summers, M., \& Mant, J. (1995) A misconceived view of subject matter knowledge in primary science education, Research Papers in Education, 10(3), 303-307. http://dx.doi.org/10.1080/0267152950100303

Trumper, R. (2001a). A cross-age study of junior high school students' conceptions of basic astronomy concepts. International Journal of Science Education, 23(11), 1111-1123. http://dx.doi.org/10.1080/09500690010025085

Trumper, R. (2001b). A cross-age study of senior high school students' conceptions of basic astronomy concepts. Research in Science and Technological Education, 19(1), 97-109. http://dx.doi.org/10.1080/02635140120046259

Trundle, K. C., Atwood, R. K., \& Christopher, J. E. (2002). Preservice elementary teachers' conceptions of moon phases before and after instruction. Journal of Research in Science Teaching, 39(7), 633-658. http://dx.doi.org/10.1002/tea.10039

Valanides, N., Gritsi F., Kampeza, M., \& Ravanis, K. (2000). Changing pre-school children's conceptions of the day/night cycle. International Journal of Early Years Education, 8(1), 27-39. http://dx.doi.org/10.1080/096697600111725

Vosniadou, S., \& Brewer, W. F. (1994). Mental models of the day/night cycle. Cognitive Science, 18, 123-184. http://dx.doi.org/10.1207/s15516709 $\operatorname{cog} 1801 \_4$

Zeilik, M., Schau, C., \& Mattern, N. (1998). Misconceptions and their change in university-level astronomy courses. The Physics Teacher, 36(2), 104-107. http://dx.doi.org/10.1119/1.880056 


\section{Appendix}

1) Mustafa asks his 180 -cm-tall friend Ali to take 10 steps. Mustafa then covers one eye and measures Ali's height as $5 \mathrm{~cm}$ with the ruler that he holds from his eye.

Which of the following scientific facts is similar to Mustafa and Ali's experiment?
A) The Moon's mass is smaller than the Sun's
B) The Sun appears smaller than it actually is
C) The Sun looks like a globe
D) The Moon looks like a globe

2) The Earth's rotation is in the direction of the arrow. Which time of day is it then at locations K, L, M, and N?

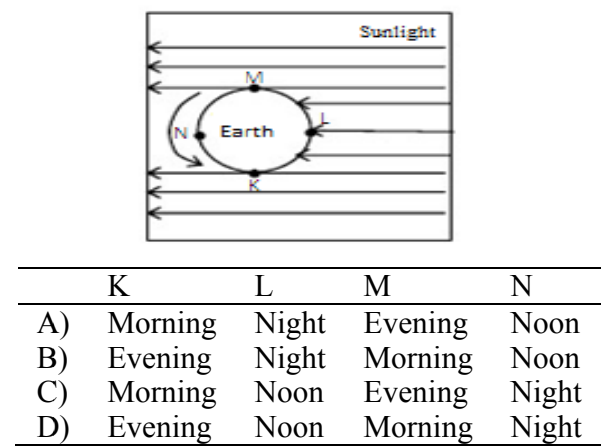

3) In a dark room, Burcu wants to model a lunar eclipse using some fruits and a burning candle. In which order below do the fruits and the burning candle best model a lunar eclipse?

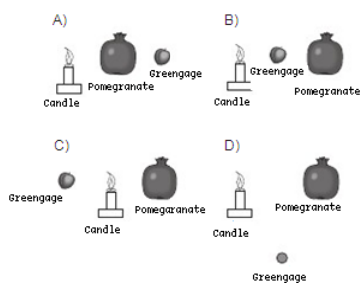

4) The day comprises both daytime and night time. This is a consequence of which of the following?

I - the distance between the Earth and the Sun

II - the Earth's rotation

III - the Earth orbiting the Sun

5)
A) Only I
B) Only II
C) I \& II
D) I \& III

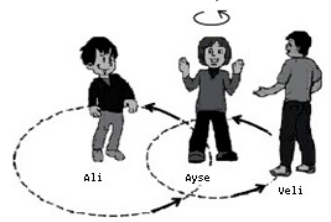

Ali, Ayşe, and Veli are playing a game in which Ali stands in the middle, Ayşe turns both around herself and around Ali, and Veli turns around Ayşe. If this game is like the movements of the Sun, the Earth, and the Moon, which of the following is then true?

6)

\begin{tabular}{llll}
\hline & Ali & Ayşe & Veli \\
\hline A) & Earth & Sun & Moon \\
B) & Sun & Moon & Earth \\
C) & Moon & Earth & Sun \\
D) & Sun & Earth & Moon \\
\hline & & & \\
& & & \\
& & & \\
& & &
\end{tabular}


In order for the observer in the illustration to see the Full Moon, where must the Moon be?
A) 1
B) 2
C) 3
D) 4

7) Which of the following can be explained by the Moon completing its rotation and its orbit around the Earth in the same period of time?
A) The Moon reflects the light it receives from the Sun
B) Viewed from the Earth, the Moon looks like a globe
C) Viewed from the Earth, the Moon always presents the same side
D) The phases of the Moon

8) Students were asked to model the movements of the Earth and the Moon in relation to the Sun.

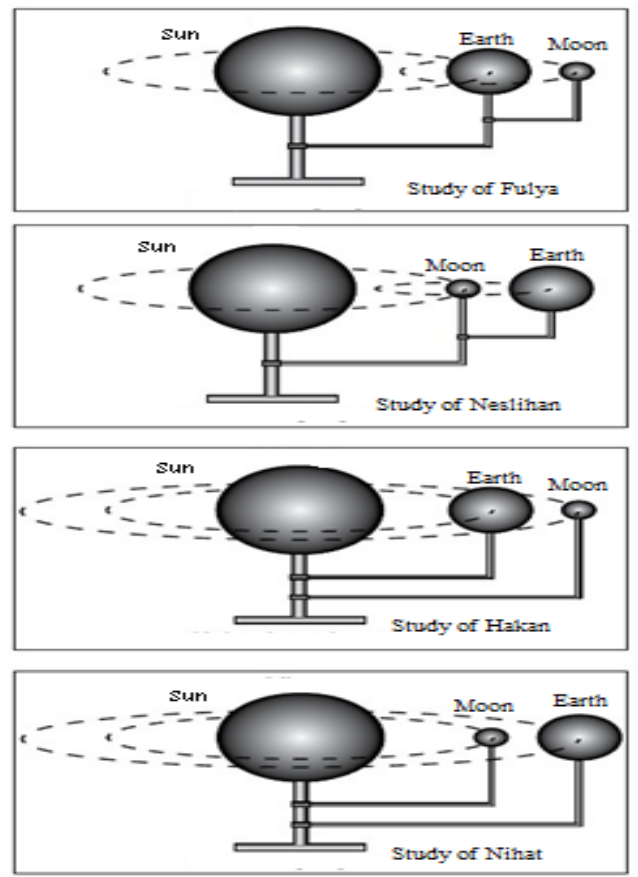

Which student's work best models the movements of the Earth and the Moon in relation to the Sun?
A) Study of Fulya
B) Study of Hakan
C) Study of Neslihan
D) Study of Nihat

9) Which of the following statements is false?
A) A day is 24 hours everywhere on the Earth
B) Night and daytime vary according to the seasons
C) It appears as if the Sun moves in the sky because the Earth orbits the Sun
D) Day and night constantly follow each other because of the Earth's rotation

10) Which of the following statements about the Moon is / are true?

I - From the Earth, we always see the same side of the Moon

II - If the Moon had its own light, it could be observed as a whole

III - The Moon completes its rotation and orbit around the Earth in the same period of time
A) Only I
B) I-II
C)II-III
D) I-II-III 
11)

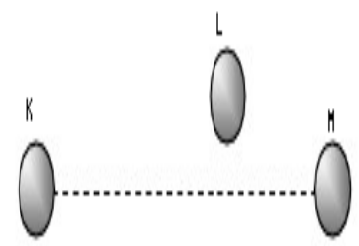

$\mathrm{K}$, $\mathrm{L}$, and $\mathrm{M}$ are celestial bodies ordered as shown in the illustration. $\mathrm{K}$ and $\mathrm{L}$ are known to be of equal size. An observer on $\mathrm{K}$ perceives $\mathrm{L}$ and $\mathrm{M}$ to be of equal size. Which of the following are then true?

$\mathrm{I}-\mathrm{M}$ is actually larger than $\mathrm{M}$

II - An observer on $\mathrm{L}$ perceives $\mathrm{K}$ and $\mathrm{M}$ of equal size.

III - An observer on M perceives L as larger than $\mathrm{K}$.
A) Only I
B) I \& III
C) II \& IIID) I \& II \& III

12)

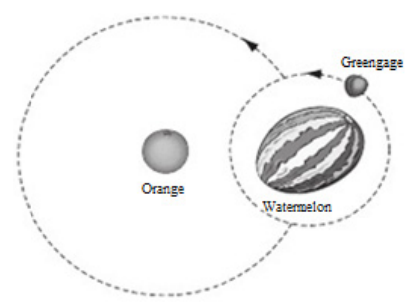

Can uses fruits to model the Earth, the Sun, and the Moon as shown in the illustration. His teacher warns him of an error in his model. Which of the following changes can Can make to better represent the three bodies?

A) Switch the watermelon and the plum

B) Switch the plum and the orange

C) Switch the orange and the watermelon

D) Move the plum away from the watermelon and place it next to the orange

13)

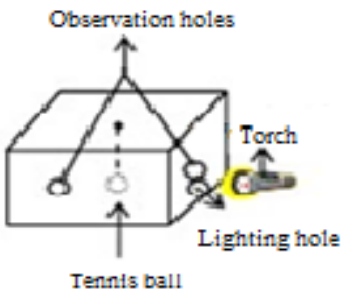

An observer hangs a tennis ball right in the centre of a cardboard box and makes holes for lighting and observation, as shown in the illustration. From the lighting hole, he illuminates the inside of the box with a torch. Then, he looks through the four observation holes and draws what the tennis ball looks like. Which bodies do the tennis ball, the torch, and the observer represent in this observation?

\begin{tabular}{llll}
\hline & Observer & Torch & Tennis ball \\
\hline A) & Sun & Moon & Earth \\
B) & Earth & Sun & Moon \\
C) & Moon & Earth & Sun \\
D) & Moon & Sun & Earth \\
\hline
\end{tabular}

\section{$(\mathrm{cc}) \mathrm{EY}$}

This work is licensed under a Creative Commons Attribution 3.0 License. 